\title{
Multidisciplinary protocol for the management of fibromyalgia associated with imbalance. Our experience and literature review
}

1. Department of Physical Medicine and Rehabilitation, University of Catania. 95125 Catania, Italy; 2. General Medicine, ASP Siracusa. 96100 Siracusa, Italy; 3. Pain Medicine Department. University of Catania. 95125 Catania, Italy.

http://dx.doi.org/10.1590/1806-9282.65.10.1265

\begin{abstract}
SUMMARY
OBJECTIVE: We reported our multidisciplinary protocol for the management of fibromyalgia associated with imbalance. Our aim was to verify the effectiveness of a proprioceptive training program as a complementary therapy for a traditional protocol of education, mindfulness, and exercise training for the management of fibromyalgia associated with imbalance.

METHODS: Retrospective cohort study on 84 women, with primary fibromyalgia associated to imbalance. A group of patients performed traditional exercise training; in a second group the training was supplemented with proprioception exercises. Each session lasted from 40 to 60 minutes and was performed three times a week for 12 weeks.

RESULTS: After three months of training and eight months after the end of the training, the balance evaluation revealed significant differences in the comparison of the Timed Up and Go test, Berg Balance Scale, and Tinetti scale with the baseline, there was a better improvement in the proprioceptive training group $(p<0.05)$. A reduction in pain and improvement in functional and muscular performance and quality of life were observed in both groups ( $p<0.05)$, but with no significant differences between them in the Numeric Pain Rating Scale, Fibromyalgia Impact Questionnaire, and Short Form Health Survey ( $p>0.05)$. Fifteen months after the end of the program, the effects of training were not maintained.

CONCLUSION: The present study revealed that training supplemented with proprioception exercises has beneficial effects on clinical findings and improves balance in patients with fibromyalgia, even if the positive results did not persist after the interruption of the rehabilitative program in the long term.
\end{abstract}

KEYWORDS: Fibromyalgia. Postural balance. Chronic pain. Clinical protocols. Quality of life.

\section{INTRODUCTION}

Imbalance in fibromyalgia

Fibromyalgia (FM) is a chronic musculoskeletal pain syndrome characterized by extensive pain and multiple tender points on physical exam ${ }^{1,2}$. Prevalence of FM is $2 \%$ in the general population, predominantly women. It often takes more than two years to make a diagnosis, with an average of 3.7 consultations with different physicians ${ }^{3}$. Patients with FM report a variety of symptoms, including muscle weakness, disabling fatigue, mood disturbance, cognitive impairment, non-restorative sleep, morning stiffness. Lack of balance and falls are part of the symptoms of FM. The balance issue in this disease must not 
be underestimated by clinicians, and the clinical examination of this symptom should not be neglected. Several studies showed increased imbalance and frequency of fall in patients with $\mathrm{FM}^{3-8}$. Dizziness was reported by $72 \%$ of the patients with $\mathrm{FM}^{5}$. A study of 2,596 patients with FM reported balance problems as one of the top 10 most debilitating symptoms with a prevalence of $45 \%{ }^{7}$. In another study, $68 \%$ of 486 patients with FM had dizziness ${ }^{8}$. Postural instability often leads to further deterioration of postural control, fear of falling, with a negative impact on endurance, muscle strength, flexibility, coordination, and quality of life in patients with $\mathrm{FM}^{4,9}$.

\section{Recommendations for the treatment of FM}

The American Pain Society (APS) ${ }^{10}$, the Association of the Scientific Medical Societies in Germany $(\mathrm{AWMF})^{11}$ and the European League against Rheumatism (EULAR) ${ }^{12}$ developed the recommendations for the treatment of FM. According to these, the treatment should be gradual and start with a group therapy session to improve awareness about the disease, as well as non-pharmacological and pharmacological modalities. Exercises involving different skills, such as strength, endurance, balance, and coordination for the management of FM, reduce the disability of these patients. Thus, the treatment of imbalance must be a prerogative of each therapy for patients with FM.

\section{Purpose}

The aim of this study was to verify the effectiveness of a proprioceptive training program as a complementary therapy of a protocol of education, mindfulness, and rehabilitation program (including aerobic and functional exercises, strength, and endurance training) for the management of fibromyalgia associated with imbalance. We reported our multidisciplinary clinical protocol for the follow-up and the management of FM associated with postural imbalance.

\section{METHODS}

All procedures performed in our study involving human participants were in accordance with the ethical standards of the institutional and/or national research committee and with the 1964 Helsinki declaration and its later amendments or comparable ethical standards. Informed consent was obtained from all the participants included in the study.

\section{Study Design and Data Collection}

We conducted a retrospective study at the Pain Medicine Department of the University of Catania from May 2017 to June 2018. A total of 144 potentially eligible outpatients were screened, 84 of whom met the inclusion criteria. The inclusion criteria were as follows: females aged between 20 and 40 years, height between 1.50 and $1.80 \mathrm{~m}$, weight between 50 and $80 \mathrm{~kg}$ and BMI in the range of 18.5 to $29.9 \mathrm{~kg} /$ $\mathrm{m}^{2}$; having a clinical diagnosis of $\mathrm{FM}$ according to the American College of Rheumatology's criteria ${ }^{2}$, diagnosed in the year previous to the research, referring also to imbalance associated with FM, with similar time from symptom onset (mean duration of the symptoms was $10 \pm 2$ months). We included patients with a sedentary lifestyle with no or irregular physical activity (patients who did not exercise in the last six months). We excluded from the study patients with a history of inflammatory rheumatic disease, musculoskeletal disorders or deformities, and mechanical problems limiting the capacity for exercise, neurological disorder, peripheral neuropathy, diabetes mellitus, unstable hypertension, severe respiratory and cardiac problems as uncontrolled hypertension, malignant tumours, inner ear disease, hearing and visual problems, patients who used antidepressant, opioid, sedative or other drugs that could interfere with balance or nutritional supplements designed to stimulate brain metabolism, patients who received psychological or physical therapy. We also excluded pregnant women. Dropouts were excluded and not considered in the study (Fig. 1).

\section{Procedures}

One group of patients carried out traditional exercises, without proprioception exercises (group $1 \mathrm{n}=$ 42 ), and a second group (group $2 \mathrm{n}=42$ ) with proprioception exercises. None of the patients were aware of the two different types of treatment they were receiving. A physician, totally unaware of the group in which each patient was inserted, was responsible for all evaluations. The rheumatologist carried out the first examination for the differential diagnosis and the confirmation of the disease. The otolaryngologist ruled out an inner ear disease causing dizziness. The physiatrist designed the rehabilitation program for the management of FM, without pharmacological treatment. If the rehabilitation exercises alone were not able to improve symptoms, the pain therapist designed a pharmacological protocol at first with 


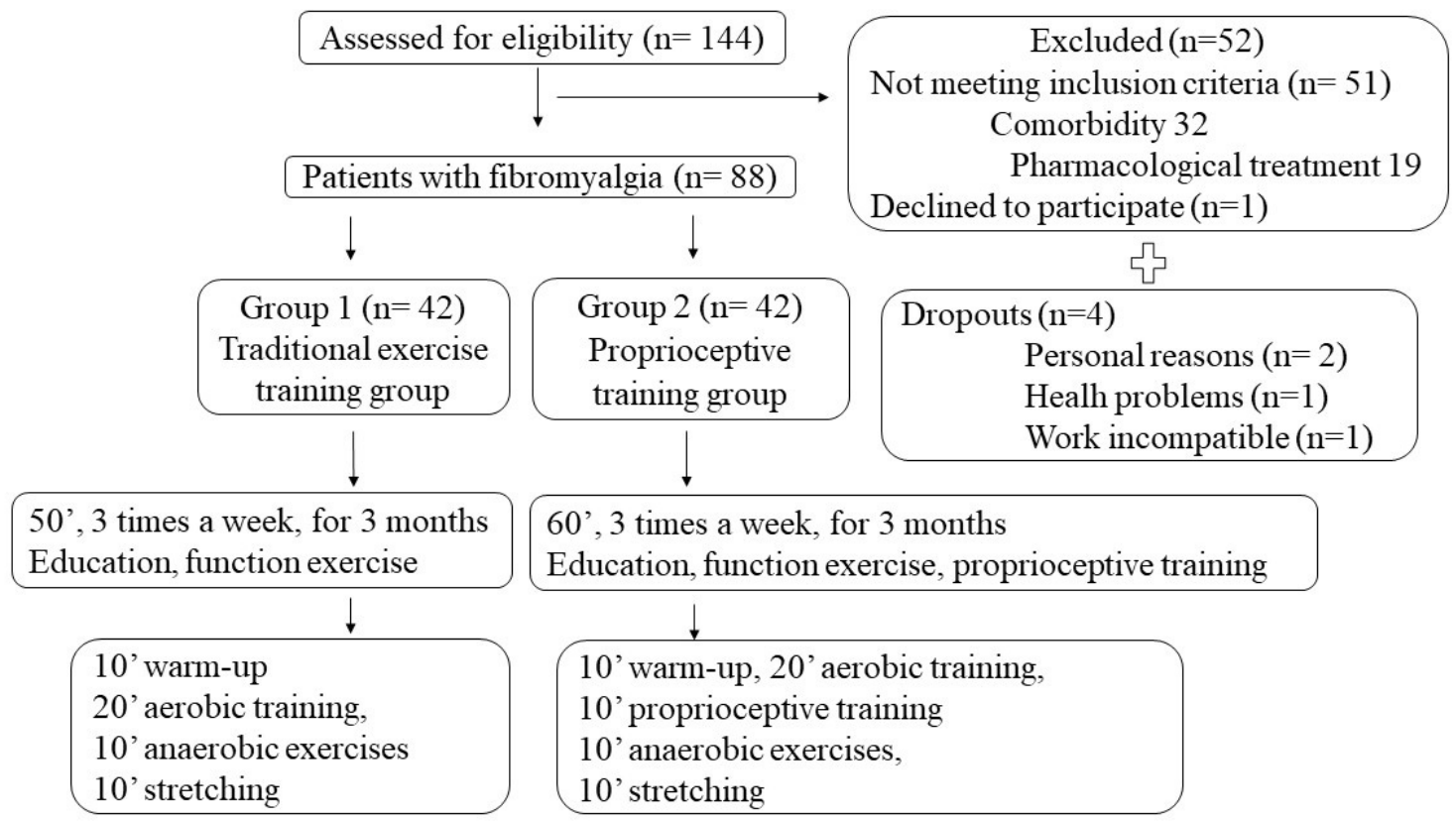

FIGURE 1. FLOW DIAGRAM OF THE PATIENTS

paracetamol, then if the pain was too severe, with non-steroidal anti-inflammatory drugs (NSAIDs), muscle relaxants, antidepressant, opioid, and sedative; in this case the patients were discontinued from the study.

The patients of both groups were evaluated before the training program, after 3 months of treatment, and 8 and 15 months after the suspension of the treatment.

At the first evaluation, before the beginning of the training and during the follow-up, all vestibular tests were normal, without neurological or peripheral vestibular lesions. Neither spontaneous nystagmus with or without visual fixation, nor positional nystagmus were found. Semont and McClure maneuvers, head-shaking test, Halmagyi head thrust maneuver, Fukuda stepping test, and Romberg's test were negative.

\section{Outcome measures}

Tenderness was measured with the tender point count; all 18 tender points were assessed according to Wolfe et al. ${ }^{2}$.

Quality of life was measured with FIQ and SF-36. We administered the Italian version of the Fibromyalgia Impact Questionnaire (FIQ) to assess FM severity, functional status, and quality of life ${ }^{13}$. This questionnaire measures 10 different features including physical functioning, status of feeling well, inability to work, difficulty in working, pain, fatigue, morning fatigue, stiffness, anxiety, and depression. The FIQ score ranges from 0 to 100; higher scores (>or=59 to $100)$ indicate a greater impact of the disease on the patients, $>$ or $=39$ to $<59$ a moderate symptomatology, 0 to $<39$ was found to represent a mild involvement of the functional status of the patients.

The pain was evaluated using the Numerical Rating Scale (NRS) from 0 to 10, with higher values indicating greater intensity ${ }^{14}$.

The balance was evaluated using the validated Italian version of the Berg Balance Scale (BBS) ${ }^{15}$ and Tinetti scale ${ }^{16}$. The BBS consists of 14 items that evaluate daily functioning. The level of competence in each activity is rated on a 5-point scale ranging from 0 (unable to do) and 4 (able to do independently and safely). The patients were asked to perform all functional parameters; the total score was calculated as the sum of the scores obtained from each parameter. The maximum score that can be obtained from the test is 56; 0-20 points indicate high fall risk, 21-40 points indicate moderate fall risk, and $41-56$ points indicate low fall risk. The Tinetti scale has 2 parts: performance-oriented assessment of balance with 16 points (sitting balance, rising from a chair, immediate standing balance in the first 3-5 seconds, standing balance, balance with eyes closed, and turning balance $\left[360^{\circ}\right]$ ) and a performance-oriented assessment of gait with 12 points (initiation of gait, step 
height, step length, step symmetry, step continuity, path deviation, trunk stability, walk stance, and turning while walking). Less than 19 points means high risk of falls, between 19 and 24 means risk of falls, and between 24 and 28 means no disturbance in gait or balance. Therefore, the cut-off point that predicts a moderate or high risk of falling and disturbance in balance and gait was 24 .

Furthermore, the patients reported the number of falls in the last 6 months.

The risk of falling and the disability was measured with the Timed Up and Go Test (TUGT) ${ }^{17}$. The patients were instructed to sit on a chair with back support. A mark was placed on the floor three meters away from the front of the chair. The patients were asked to stand up, walk to the mark on the floor, turn around, walk back to the chair, and sit down. The performance was measured in seconds. Patients with a score of $<14$ seconds were considered to have a high risk of falls.

Medical Research Council scale (MRC) was used to test hamstring and quadriceps muscle strength ${ }^{18}$. MRC grades muscle power on a scale of 0 to 5 .

The validated Italian version of the SF-36 (SF$36)^{19}$ was used to evaluate the activities of daily living (ADL). SF-36 contains 36 items on how daily activities (e.g., walking, shopping, going up some steps) have been limited by health problems. It provides a classification in 8 domains that correspond to the dimensions most related to health indication: role physical health, physical functioning, bodily pain, vitality, social functioning, role emotional, mental health, and general health. These dimensions are evaluated in a standardized 0-to-100 scale, in which the higher the score, the better the representation of health status.

The patients who took NSAIDs, muscle relaxants, antidepressant, opioid, and sedative during the study period were discontinued from the study. The patients who took paracetamol for severe pain were included.

\section{The Rehabilitation Program}

This program followed the recommendations of the American College of Sports Medicine (ACSM) ${ }^{20}$ for individuals with FM.

The same physical therapists followed the patients and supervised the sessions. For group 1, each session had two stages: a group therapy session and function exercise. This group executed a training program of 50 minutes, three times a week, for 12 consecutive weeks according to the ACSM guidelines ${ }^{20}$. Each session included: 10 minutes of warm-up with walking and warm-water exercise, 20 minutes of aerobic training, 10 minutes of resistance exercises (strength, endurance, and power), 10 minutes of stretching (table 1). Group therapy, conducted by the physiatrist, consisted of education and mindfulness intervention, each session lasted 10 minutes in a week, to encourage adherence to the rehabilitation program. Education made patients more aware of their own pathology and of therapeutic resources. Mindfulness intervention improved concentration, targeting to meet the specific needs of occupational engagement or returning to work, reduced anxiety, improved the awareness of bodily sensations. The training in the pool included 5 min of warming up with slow walks and 5 min of overall mobility using water as resistance and strength exercises. The aerobic exercises included walking on the treadmill at a speed of 6 and no inclination, core stability, the use of major muscle groups in rhythmic activities, and breathing exercises. The intensity of aerobic exercise achieved $64 \%$ of predicted maximum heart rate (range $64 \%$ to $94 \%$ according to the ACSM guidelines ${ }^{20}$ ). The resistance exercises at an intensity of the Repetition Maximum of each exercise according to ACSM guidelines ${ }^{20}$, included bilateral squats (10 sets of 30 seconds with 45 seconds of recovery between sets) and unilateral squat (8 sets of 30 seconds, with 45 seconds of recovery between sets). Stretching exercises included elongation of neck, shoulder, spine, hamstring, quadriceps, gastrocnemius (4 repetitions for each muscle group), in a position of mild discomfort for a duration of 10 to 30 seconds according to the ACSM guidelines ${ }^{20}$.

For group 2, each session had three stages: group therapy session, function exercise, and proprioceptive training. Thus, this group performed the same exercise program, with the addition of proprioceptive training for 10 minutes (agility, coordination, and balance). Proprioceptive training included the following exercises: coordination exercises with eyes open and closed, head movement (left, right, up and down) with eyes open and closed, standing on balance pads with eyes open and closed, balancing on both feet and on one foot, tandem exercises, bending exercises, lateral and backward movements, skipping, scissoring gait, rolling and twisting exercises, Freeman board training, walk on unstable ground, like sand, with eyes open and closed, postural biofeedback exercises like catch, speedball, and sky ball. 
TABLE 1. DESCRIPTION OF EXERCISES PERFORMED BY BOTH GROUPS DURING A STANDARD SESSION OF TRAINING

\begin{tabular}{|c|c|c|}
\hline Exercise & Description & Progression \\
\hline \multicolumn{3}{|l|}{ WARM-UP 10' } \\
\hline Walking & Walking & Increase in time and speed \\
\hline Swimming pool sessions & $34^{\circ} \mathrm{C}$ water & Overall mobility using water as resistance \\
\hline Core stability & With breathing exercises & \\
\hline \multicolumn{3}{|l|}{ AEROBIC EXERCISES 20' } \\
\hline Walking on the treadmill & With an initial speed of 6 and no inclination & Increase in time and speed \\
\hline \multicolumn{3}{|l|}{ ANAEROBIC EXERCISES 10' } \\
\hline \multicolumn{3}{|l|}{ Lower limb exercises } \\
\hline $\begin{array}{l}\text { Anterior, lateral, zigzag, and circles } \\
\text { straight leg raise }\end{array}$ & In supine or side-lying & Increase in external resistance (elastic band) \\
\hline Hip exercise & $\begin{array}{l}\text { Side-lying with knee extension. Horizontal } \\
\text { hip abduction }\end{array}$ & $\begin{array}{l}\text { Increase in external resistance (elastic band) /isome- } \\
\text { try at the end of the series (10 s) }\end{array}$ \\
\hline Bridge exercise & - & Bipodal and unipodal support \\
\hline Stand up and sit down & - & Straight back \\
\hline $\begin{array}{l}\text { Mini squats with bipodal and unipodal } \\
\text { support }\end{array}$ & $\begin{array}{l}\text { Bilateral squats: } \\
8 \text { sets of } 30 \text { seconds with } 45 \text { seconds of } \\
\text { recovery between sets }\end{array}$ & $\begin{array}{l}\text { Unilateral squat: } 5 \text { sets of } 30 \text { seconds, with } 45 \text { seconds } \\
\text { of recovery between sets }\end{array}$ \\
\hline Forward lunge & - & Sideway lunge \\
\hline Up and down stairs & - & Load in the ankle (1 kg) \\
\hline Calf raises & - & Bipodal and unipodal support \\
\hline \multicolumn{3}{|l|}{ Upper limb exercises } \\
\hline Shoulders elevation & Shoulder flexion on scapular plane & Increase external resistance (elastic band) \\
\hline Pull back exercise & $\begin{array}{l}\text { Shoulder extension + elbow flexion + scapu- } \\
\text { lar adduction }\end{array}$ & Increase external resistance (elastic band) \\
\hline Pull down exercise & Shoulder extension with straight elbow & Increase in external resistance (elastic band) \\
\hline Push up exercise & - & Upper support on step \\
\hline \multicolumn{3}{|l|}{ Trunk exercises } \\
\hline Elbow plank exercise & Support on knee & Increase in time \\
\hline One side plank exercise & In side-lying & Increase in time \\
\hline \multicolumn{3}{|l|}{ PROPRIOCEPTIVE TRAINING 10' } \\
\hline $\begin{array}{l}\text { Coordination exercises with open and } \\
\text { closed eyes }\end{array}$ & $\begin{array}{l}\text { Movement with the head (head left, right, } \\
\text { up and down }\end{array}$ & Balancing on both feet and one foot \\
\hline Unipodal balance & Stand on one leg whit opened eyes ( $3 \times 1$ min) & $\begin{array}{l}\text { Associate tasks with upper limbs and with contralat- } \\
\text { eral lower limb }\end{array}$ \\
\hline Stand up and sit down & - & Bipodal and unipodal support \\
\hline Standing on balance pads & With eyes open and closed & Balancing on both feet and one foot \\
\hline $\begin{array}{l}\text { Tandem exercises, bending exercises, } \\
\text { lateral and backward movements, } \\
\text { skipping, scissoring gait, rolling and } \\
\text { twisting exercises, }\end{array}$ & With eyes open and closed & Balancing on both feet and one foot \\
\hline Freeman board training & Walk on unstable ground, like sand & During dual-task like forward counting \\
\hline Postural biofeedback exercises & Catch, speedball, sky ball & With more coordination \\
\hline \multicolumn{3}{|l|}{ STRETCHING 10' } \\
\hline Flexibility exercises & $\begin{array}{l}\text { Static stretching of great muscles groups: } \\
\text { elongation of neck, shoulder, spine, ham- } \\
\text { string, quadriceps, gastrocnemius }\end{array}$ & $\begin{array}{l}6 \text { repetitions for each muscle group. Increase in time } \\
(5-10 \mathrm{~min})\end{array}$ \\
\hline Breathing exercises & With accessory respiratory muscles & For 3 minutes \\
\hline
\end{tabular}

The program had a progressive difficulty in execution, such as an increase in external resistance, load, duration and number of exercises, number of series and repetitions, rest time between sets, and speed of movement execution.

\section{Statistical Analysis}

The Statistical Package for Social Sciences (SPSS, Version 18.0 for Windows; SPSS Inc., Chicago, IL) was used for data analysis. Quantitative data were expressed as mean and standard deviation and were 
compared using the t-test. $\mathrm{P}<.05$ was considered with statistical significance.

\section{RESULTS}

One group of patients performed traditional training, without proprioception exercises (group $1 \mathrm{n}=42$ ), and the second group (group $2 \mathrm{n}=42$ ) with proprioception exercises. At baseline, the patients of both groups were homogeneous for general clinical features, clinical characteristics, and relevant socio-demographic characteristics (age, body mass index, education, and occupation). The patients with FM associated to imbalance had similar symptoms: sleep disturbances were present in $35 \%$, paraesthesia in $30 \%$, stiffness in 35\%, fatigue and dizziness in $100 \%$, headache in $20 \%$, irritable bowel syndrome in $60 \%$, depression in $45 \%$, anxiety in $10 \%$.

No adverse events, exacerbations, or injuries occurred during the treatment in both groups.

Several patients of both groups took paracetamol: 19 of group 1 and 21 of the group $2(1 \mathrm{mg} /$ day for a mean time of 15 non-consecutive days when they had pain).

At the moment of the diagnosis, the mean number of the FM tender points was 14 out of 18 in both groups $(\mathrm{P}>.05)$. At the end of the training and 8 months after program completion, the mean number of FM tender points was 12, without a statistical difference between the two groups ( $>>$.05) (Table 2). Fifteen months after the program completion, the mean number of FM tender points was similar to the results at baseline (Table 2).

At the first evaluation, the initial score of FIQ was 56 in both groups (a moderate involvement of the functional status of the patients). At the end of the training and 8 months after the end of the program, there were significant improvements in FIQ values in both groups (mean FIQ Score 38$)(\mathrm{P}<.05)$, showing just a mild involvement of the functional status of the patients, without a significant difference between the two groups $(\mathrm{P}>$.05) (Table 2). Fifteen months after the program completion, the evaluation showed no significant differences in these scale scores, with similar score obtained at the beginning of training in both groups (Table 2).

At the first evaluation, the pain was referred to as very high (9 out 10 in NRS). At the end of the training and 8 months after the end of exercises, there was a significant reduction of pain in both groups $(\mathrm{P}<.05)$, without a significant difference in the NRS score between the groups $(\mathrm{P}>$.05) (Table 2). Fifteen months after the program completion, the evaluation showed no significant differences in these scale scores, with a similar score to that obtained at the beginning of training in both groups (Table 2).

Before the beginning of the training, patients of both groups reported a mean of 31 falls over the last twelve months, without a statistical difference between the two groups $(\mathrm{P}>$.05). From the end of the training until 8 months after the end of the training, the patients of group 1 reported a mean of 21 falls, the patients of group 2 reported 8 falls, the mean number of falls was significantly lower in group 2 compared to group $1(\mathrm{P}<$.05) (Table 2). Thus, significant relationships were detected between the number of falls and proprioception exercises.

At the beginning of the study, both groups were at risk of falling, according to the TUGT score (mean duration of the best performance was 19 seconds), the BBS score (mean BBS score: 28), and Tinetti (mean score: 26), without a statistical different between the two groups $(\mathrm{P}>.05)$. At the end of the training and 8 months after the end of the program, the difference in the values between the two groups revealed a significant statistical difference in the BBS score, in the Tinetti and in the TUGT scores with an improvement of 9 seconds in the group $2(\mathrm{P}<.05)$ (Table 2$)$. Thus, in TUGT, BBS, and Tinetti scales the effects of training persisted for 8 months after the end of exercises in group 2, with the same scores obtained at the end of the training. Fifteen months after the program completion, the evaluation showed no significant differences in these scale scores, with a similar score to that obtained at the beginning of training in both groups (Table 2).

Compared to the evaluation at the beginning of the study, at the end of the training and 8 months after the end of the program, according to the MRC, there was a statistically significant increase in quadriceps, hamstring, and gastrocnemius strength in both groups (initial mean score: 3 ; mean score at the end of the program 5$)(\mathrm{P}<.05)$, without a significant difference between the two groups $(\mathrm{P}>$.05) (Table 2). Fifteen months after the end of the program, the improvements in strength were not maintained (Table 2).

At the baseline, in both groups, mean SF-36 scores were lower than those of age- and gender-matched population, especially for pain, fatigue, and mobility (mean scores for pain 36, fatigue 35, mobility 
TABLE 2. ABOVE THE SCORES OF GROUP 1 AND 2 AT BASELINE, IMMEDIATELY AFTER TREATMENT, AND 8 MONTHS AFTER TREATMENT (PAIRED T-TEST). THEN THE STATISTICAL DIFFERENCE BETWEEN THE TWO GROUPS IMMEDIATELY AFTER TREATMENT, 8 AND 15 MONTHS AFTER TREATMENT (IMPAIRED T-TEST).

\begin{tabular}{|c|c|c|c|c|c|c|c|c|c|c|c|c|}
\hline \multirow[t]{3}{*}{ Scales } & $\begin{array}{l}\text { Group } 1 \\
\text { Score }\end{array}$ & $\begin{array}{l}\text { Group } 1 \\
\text { Score }\end{array}$ & $\begin{array}{l}\text { Group } 1 \\
\text { Paired t } \\
\text { Test }\end{array}$ & $\begin{array}{l}\text { Group } 1 \\
\text { P value }\end{array}$ & \multicolumn{2}{|c|}{ IC-95\% } & $\begin{array}{l}\text { Group } 2 \\
\text { Score }\end{array}$ & $\begin{array}{l}\text { Group } 2 \\
\text { Score }\end{array}$ & $\begin{array}{l}\text { Group } 2 \\
\text { Paired t } \\
\text { Test }\end{array}$ & $\begin{array}{l}\text { Group } 2 \\
\text { P value }\end{array}$ & \multicolumn{2}{|c|}{ IC-95\% } \\
\hline & At TO & AF and $8 \mathrm{~m}$ & $\begin{array}{l}\text { AF and } \\
8 \mathrm{~m}\end{array}$ & $\begin{array}{l}\mathrm{AF} \text { and } \\
8 \mathrm{~m}\end{array}$ & \multicolumn{2}{|c|}{ Group 1} & At TO & $\begin{array}{l}\mathrm{AF} \text { and } \\
8 \mathrm{~m}\end{array}$ & $\mathrm{AF}$ and $8 \mathrm{~m}$ & $\begin{array}{l}\mathrm{AF} \text { and } \\
8 \mathrm{~m}\end{array}$ & \multicolumn{2}{|c|}{ Group 2} \\
\hline & & & & & $\begin{array}{l}\text { Lower } \\
\text { limit }\end{array}$ & $\begin{array}{l}\text { Upper } \\
\text { limit }\end{array}$ & & & & & $\begin{array}{l}\text { Lower } \\
\text { limit }\end{array}$ & $\begin{array}{l}\text { Upper } \\
\text { limit }\end{array}$ \\
\hline $\begin{array}{l}\text { Tender } \\
\text { points }\end{array}$ & $14 \pm 2.14$ & $12 \pm 0.70$ & $\mathrm{t} 1.58$ & $p>0.05$ & 0.62 & 1.48 & $14 \pm 2.24$ & $31 \pm 3.54$ & $t 1.62$ & $p>0.05$ & -6.49 & 4.74 \\
\hline N. falls & $31 \pm 3.84$ & $21 \pm 3.45$ & t 1.90 & $p>0.05$ & 1.61 & 3.82 & $31 \pm 3.54$ & $8 \pm 4.01$ & t 1.96 & $p>0.05$ & 5.08 & 7.37 \\
\hline $\mathrm{FIQ}$ & $56 \pm 5.07$ & $38 \pm 7.02$ & t 2.68 & $p<0.05$ & 1.11 & 4.77 & $56 \pm 8.02$ & $38 \pm 7.65$ & t 2.69 & $p<0.05$ & -0.36 & 4.38 \\
\hline NRS & $9 \pm 1.05$ & $6 \pm 0.98$ & t 2.79 & $p<0.05$ & 0,29 & 2.72 & $9 \pm 1.90$ & $5 \pm 0.95$ & $\mathrm{t} 2.72$ & $p<0.05$ & 2.12 & 2.98 \\
\hline TUGT & $19 \pm 1.08$ & $10 \pm 2.01$ & t 1.23 & $p>0.05$ & 0.93 & 4.34 & $19 \pm 2.01$ & $10 \pm 1.85$ & t 1.48 & $p>0.05$ & 4.11 & 5.28 \\
\hline BBS & $28 \pm 3.01$ & $35 \pm 2.89$ & $\mathrm{t} 1.52$ & $p>0.05$ & -3.31 & $-1,53$ & $28 \pm 4.25$ & $44 \pm 6.01$ & t 1.60 & $p>0.05$ & -4.40 & -1.29 \\
\hline \multirow[t]{4}{*}{ MRC } & $3 \pm 0.04$ & $5 \pm 0.05$ & $\mathrm{t} 2.72$ & $p<0.05$ & -44.72 & -44.69 & $3 \pm 0.12$ & $5 \pm 0.62$ & t 3.98 & $P<0.05$ & -4.57 & 4.35 \\
\hline & Group 1 & Group 2 & $\begin{array}{l}\text { Impaired } \\
\mathrm{t} \text {-Test }\end{array}$ & P-value & \multicolumn{2}{|c|}{ IC-95\% } & Group 1 & Group 2 & $\begin{array}{l}\text { Impaired } \\
\mathrm{t} \text {-Test }\end{array}$ & P-value & \multicolumn{2}{|l|}{ IC-95\% } \\
\hline & $\begin{array}{l}\text { AF and } \\
8 \mathrm{~m}\end{array}$ & $\mathrm{AF}$ and $8 \mathrm{~m}$ & $\begin{array}{l}\mathrm{AF} \text { and } \\
8 \mathrm{~m}\end{array}$ & $\begin{array}{l}\text { AF and } \\
8 \mathrm{~m}\end{array}$ & \multicolumn{2}{|c|}{$\mathrm{AF}$ and $8 \mathrm{~m}$} & $15 \mathrm{~m}$ & $15 \mathrm{~m}$ & $15 \mathrm{~m}$ & $15 \mathrm{~m}$ & \multicolumn{2}{|l|}{$15 \mathrm{~m}$} \\
\hline & & & & & $\begin{array}{l}\text { Lower } \\
\text { limit }\end{array}$ & $\begin{array}{l}\text { Upper } \\
\text { limit }\end{array}$ & & & & & $\begin{array}{l}\text { Lower } \\
\text { limit }\end{array}$ & $\begin{array}{l}\text { Upper } \\
\text { limit }\end{array}$ \\
\hline $\begin{array}{l}\text { Tender } \\
\text { points }\end{array}$ & $12 \pm 0.50$ & $12 \pm 0.25$ & t 0.05 & $p>0.05$ & -0.15 & 0.08 & $14 \pm 0.50$ & $13 \pm 0.25$ & t 0.06 & $p>0.05$ & 2.41 & 2.64 \\
\hline N. of falls & $21 \pm 2.01$ & $8 \pm 1.06$ & $\mathrm{t} 2.71$ & $p<0.05$ & 7.58 & 8.51 & - & - & - & - & - & \\
\hline $\mathrm{FIQ}$ & $38 \pm 1.98$ & $38 \pm 2.51$ & t 0.09 & $p>0.05$ & -0.60 & 0.76 & $51 \pm 2.98$ & $52 \pm 1.51$ & t 0.10 & $p>0.05$ & -1.33 & 0.03 \\
\hline NRS & $6 \pm 0.10$ & $5 \pm 0.19$ & t 0.65 & $p>0.05$ & 6.64 & 6.72 & $8 \pm 0.10$ & $8 \pm 0.19$ & t 0.68 & $p>0.05$ & -0.03 & 0.06 \\
\hline Tinetti & $25 \pm 3.01$ & $22 \pm 2.74$ & t 3.09 & $p<0.05$ & 0.14 & 1.88 & $26 \pm 1.01$ & $25 \pm 1.74$ & t 1.06 & $p>0.05$ & 0.41 & 1.24 \\
\hline \multirow[t]{2}{*}{ MRC } & $5 \pm 0.05$ & $5 \pm 0.09$ & t 0.81 & $p>005$ & -0.02 & 0.03 & $4 \pm 0.05$ & $4 \pm 0.09$ & t 0.84 & $P>005$ & -0.02 & 0.03 \\
\hline & Group 1 & Group 2 & $\begin{array}{l}\text { Impaired } \\
\mathrm{t} \text {-Test }\end{array}$ & P-value & \multicolumn{2}{|c|}{ IC-95\% } & & & & & & \\
\hline $\begin{array}{l}\text { SF-36 } \\
\text { after } \\
\text { treatment }\end{array}$ & & & & & $\begin{array}{l}\text { Lower } \\
\text { limit }\end{array}$ & $\begin{array}{l}\text { Upper } \\
\text { limit }\end{array}$ & & & & & & \\
\hline Pain & $50 \pm 3.84$ & $52 \pm 4.03$ & t 0.38 & $p>0.05$ & -1.68 & 0.70 & - & - & - & - & - & - \\
\hline Fatigue & $52 \pm 2.01$ & $51 \pm 2.10$ & t 0.45 & $p>0.05$ & -0.12 & 1.13 & - & - & - & - & - & - \\
\hline Mobility & $39 \pm 2.86$ & $56 \pm 4.02$ & $\mathrm{t} 2.71$ & $p<0.05$ & -5.80 & -3.72 & - & - & - & - & - & - \\
\hline
\end{tabular}

Abbreviations: Group 1 exercise training group without proprioception exercises, Group 2 group with proprioception training, \pm standard deviation, FIQ Fibromyalgia Impact Questionnaire, NRS Numerical Rating Scale, TUGT Timed Up and Go Test, BBS Berg Balance Scale, MRC Medical Research Council scale, AF immediately after treatment, 8m four months after treatment, TO at baseline, IC confidence interval, N. numbers. Results reported as mean effect sizes (Cohen's d) (95\% confidence interval (95\%).

37), without a statistical difference between the two groups ( $\mathrm{P}>$.05) (Table 2). At the end of the training and 8 months after the end of the program, a significant improvement was seen in pain and fatigue in both groups; whereas 15 months after the end of the program, the scores were similar to the results at the baseline.

The training protocol we proposed included 10 minutes of warm-water exercise, 20 minutes of aerobic training, 10 minutes of resistance exercises, 10 minutes of stretching, and 10 minutes of proprioceptive training.

\section{DISCUSSION}

In this study, we observed that the combination of traditional exercises and proprioceptive training reduced pain and fatigue and increased muscular performance. A proprioceptive training program as a complementary therapy for the management of fi- 
bromyalgia associated with imbalance must be part of the rehabilitation program. The results suggested that the benefits provided by the proprioceptive program did not include additional gains in muscular performance. Furthermore, we propose a multidisciplinary clinical approach to guide patients from diagnosis to recurrence of pain. Our diagnostic protocol included the following assessments and scales: vestibular tests, the number of tender points, FIQ, NRS, BBS, Tinetti scale, TUGT, the number of falls in the last 6 months, MRC, and SF-36.

Studies such as ours discuss the benefits of aerobic and resistance exercise in FM patients; we added proprioceptive training in FM patients to improve balance and decrease the fear of falling. The treatment for FM should focus first on non-pharmacological therapies, such as aerobic and strengthening exercises, proprioception exercises, warm-water exercise, for its availability, absence of adverse drug reactions, and relatively low $\operatorname{cost}^{21}$. We showed the effects of training for pain, strength, quality of life, and the functional consequences in FM, after 3 months of physical exercises and at 8 and 15 months after the suspension of training. Adding the proprioception exercises, we reported a significant improvement in balance, mobility, and a reduction of the number of falls too.

There is strong evidence that exercise is effective in the treatment of the signs and symptoms of FM, but there are no clear diagnostic and therapeutic protocol $^{522,23}$. Two studies showed good results in practicing multimodal exercises involving different skills such as strength, endurance, balance, and coordination for pain management, fatigue, and muscle weakness, thus reducing the impact of the disease on the QoL of these subjects ${ }^{23,24}$.

To improve the ADL, better outcomes have been obtained from aerobic, strengthening, stretching and flexibility exercises, and water exercises ${ }^{25-27}$. In addition to these classical programs, our protocol was based on proprioception exercises and focused on minimizing fatigue and pain by increasing the level of activity and balance. In another study, the benefits of aerobic training were found to be more significant than balance training ${ }^{28}$. Two studies have found that aerobic exercise is useful to improve the FIQ score, and it is considered the standard treatment for $\mathrm{FM}^{7,29}$. A meta-analysis reported that aerobic exercise for patients with FM should be performed at a slight to moderate intensity, two to three times a week, for at least four weeks ${ }^{22}$. Accordingly, in our study, we established that exercise training, three times a week, for three months, led to an improvement in FM symptoms, maintained during the following eight months. Another study showed that uninterrupted training programs should be essential in the management of patients with FM, because training programs had short-term beneficial effects on clinical signs and dynamic balance ${ }^{30}$. Some studies have found improvements in balance and motor control in response to multimodal training programs with strength training in patients with $\mathrm{FM}^{31}$. Concurrent strength and endurance training in low to moderate intensity is beneficial to patients with FM, improves the muscle strength and functional performance, and reduces symptoms, fatigue in particu$\operatorname{lar}^{32}$. Several studies have shown that short periods (5-24 weeks) of water exercise improve neuromuscular conditions ${ }^{33}$, physical fitness ${ }^{34}$, and quality of life $^{33}$. Long-lasting therapy in warm water improves muscle strength, physical problems, emotional problems, mental health, and balance ${ }^{12}$. Meditative movement (yoga, tai chi, qigong, or body awareness therapy) improves sleep and fatigue in the longer term in FM too ${ }^{12}$.

In the literature, several studies were conducted on the efficacy of training programs in patients with FM and were focused on symptoms of fatigue and pain $^{35}$. The number of studies on training programs for balance disorders with an accurate description is limited $^{36}$. Even if few studies were directed towards balance dysfunction, imbalance and gait disorders are common symptoms of FM. The increased number of falls in patients with FM is due to imbalance and also to other risk factors, such as pain, muscle weakness, cognitive disturbance, mobility limitations, use of psychotropic drugs. Several drugs, including muscle relaxants, antidepressant drugs, or opioids, which are used commonly by patients with FM, can disturb the balance and are related to falls. Jones et al. ${ }^{4}$ reported that 44 to $74 \%$ of patients with FM used such drugs.

Some studies have shown that training improves clinical findings, such as pain, physical function, proprioception, balance, and walking, through stimulation of mechanoreceptors, muscle fibers, and tactile receptors $^{30,37}$. Thus, Gusi et al. ${ }^{38}$ reported improvements in balance using a vibratory platform, the whole-body vibration (WBV). Sañudo et al. ${ }^{29}$ reported similar results and demonstrated that a traditional 
exercise program, supplemented with WVB training, could improve balance in $\mathrm{FM}^{29}$.

\section{CONCLUSIONS}

We recommend that non-pharmacological therapy should be the first-line therapy. The present study showed that traditional exercises (aerobic and resistance exercises and stretching) reduce pain, increase strength, improve exercise capacity, and enhance the quality of life in patients with FM, even if the positive results were not maintained after the interruption of rehabilitative program. The most effective type of exercise for balance is proprioceptive training. Thus, these training programs associated with balance exercises show improvements in FM symptoms (pain, fatigue) and could improve balance and maintain stability, reducing the fear of falling and the number of falls. A balance evaluation is required, and a more specific treatment protocol is needed in patients with FM associated with imbalance. We reported our multidisciplinary clinical protocol for the management of FM associated with postural imbalance.
After three months of training, the balance evaluation revealed significant differences in the TUGT, BBS, and Tinetti scale scores compared to the baseline, with a better improvement in the proprioceptive training group. Eight months after the end of the training, the patients maintained improved performance. After 15 months, the effects of training on balance and on the specific symptoms of the disease were not maintained. It is necessary to maintain proprioceptive ability by continuing the exercises after the end of the physiotherapy program. We recommend repeating the cycle of exercises with our protocol twice a year to maintain the effects of the program.

The theme is relevant, considering that recent studies show that a high proportion of individuals with fibromyalgia present balance problems. We showed the importance of a multidisciplinary clinical approach with a rheumatologist, pain therapist, physiatrist, physiotherapist, and also otolaryngologist to rule out an inner ear disease that might be causing dizziness, to follow the progression of the disease, design a protocol for the management of FM and a program of preventive care.

\section{RESUMO}

OBJETIVO: Relatamos nosso protocolo multidisciplinar para o manejo da fibromialgia associada ao desequilíbrio. Nosso objetivo foi verificar a eficácia do programa de treinamento proprioceptivo como terapia complementar de um protocolo tradicional (exercícios aeróbicos, de resistência e flexibilidade).

MÉTODOS: Estudo retrospectivo em 84 mulheres com fibromialgia primária associada a desequilíbrio. Um grupo de pacientes realizou o treinamento tradicional; em um segundo grupo o treinamento foi complementado com exercícios de propriocepção. Cada sessão durou de 40 a 60 minutos e foi realizada três vezes por semana durante 12 semanas.

RESULTADOS: Após três meses de treinamento e oito meses após o término do treinamento, a avaliação do equilíbrio revelou diferenças significativas nos testes Timed Up and Go, Escala de Equilíbrio de Berg e Escala de Tinetti em comparação com a linha de base, com uma melhora maior no grupo de treinamento proprioceptivo $(p<0,05)$. Redução da dor e melhora do desempenho funcional e muscular e da qualidade de vida foram observadas em ambos os grupos ( $p<0,05)$, mas sem diferenças significativas entre eles na Escala Numérica de Dor, Fibromyalgia Impact Questionnaire e Short Form Health Survey $(p>0,05)$. Quinze meses após o final do programa, os efeitos do treinamento não foram mantidos.

CONCLUSÃO: O presente estudo revelou que o treinamento suplementado com exercícios de propriocepção tem efeitos benéficos sobre os achados clínicos e melhora o equilíbrio em pacientes com fibromialgia, mesmo que os resultados positivos não tenham persistido após a interrupção do programa de reabilitação no longo prazo.

PALAVRAS-CHAVE: Fibromialgia. Equilíbrio postural. Dor crônica. Protocolos clínicos. Qualidade de vida.

\section{REFERENCES}

1 Arnold LM, Bennett RM, Crofford LI, Dean LE, Clauw D|, Goldenberg DL, et al. AAPT diagnostic criteria for fibromyalgia. J Pain. 2019;20(6):611-28.

2 Wolfe F, Clauw D|, Fitzcharles MA, Goldenberg DL, Katz RS, Mease P, et al. The American College of Rheumatology preliminary diagnostic criteria for fibromyalgia and measurement of symptom severity. Arthritis Care Res (Hoboken). 2010;62(5):600-10.

3 Queiroz LP. Worldwide epidemiology of fibromyalgia. Curr Pain Headache Rep. 2013;17(8):356.
4 Jones KD, Horak FB, Winters-Stone K, Irvine JM, Bennett RM. Fibromyalgia is associated with impaired balance and falls. I Clin Rheumatol. 2009;15(1):16-21.

5 Rosenhall U, Johansson G, Orndahl G. Otoneurologic and audiologic findings in fibromyalgia. Scand J Rehabil Med. 1996;28(4):225-32.

6 Russek LN, Fulk GD. Pilot study assessing balance in women with fibromyalgia syndrome. Physiother Theory Pract. 2009;25(8):555-65.

7 Bennett RM, Jones |, Turk DC, Russell IJ, Matallana L. An internet survey 
of 2,596 people with fibromyalgia. BMC Musculoskelet Disord. 2007;8:27.

8 Katz R, Ferbert S, Leavitt F. Fibromyalgia patients report many symptoms other than pain and fatigue. Arthritis Rheum. 2007;56(9S):1532.

9 Muto LH, Sauer JF, Yuan SL, Sousa A, Mango PC, Marques AP. Postural control and balance self-efficacy in women with fibromyalgia: are there differences? Eur J Phys Rehabil Med. 2015;51(2):149-54.

10 Burckhardt CS, Goldenberg D, Crofford L, Gerwin R, Gowans S, Kackson, et al. Guideline for the management of fibromyalgia syndrome. Pain in adults and children. APS Clinical Practice Guideline Series No. 4. Glenview: American Pain Society; 2005

11 Klement A, Häuser W, Brückle W, Eidmann U, Felde E, Herrmann M, et al. Principles of treatment, coordination of medical care and patient education in fibromyalgia syndrome and chronic widespread pain. Schmerz. 2008;22(3):283-94.

12 Macfarlane G], Kronisch C, Atzeni F, Häuser W, Choy EH, Amris K, et al. EULAR recommendations for management of fibromyalgia. Ann Rheum Dis. 2017;76(12):e54.

13 Sarzi-Puttini P, Atzeni F, Fiorini T, Panni B, Randisi G, Turiel M, et al. Validation of an Italian version of the Fibromyalgia Impact Questionnaire (FIQ-I). Clin Exp Rheumatol. 2003;21(4):459-64.

14 Jensen MP, Turner JA, Romano JM. What is the maximum number of levels needed in pain intensity measurement? Pain. 1994;58(3):387-92.

15 Ottonello M, Ferriero G, Benevolo E, Sessarego P, Dughi D. Psychometric evaluation of the Italian version of the Berg Balance Scale in rehabilitation inpatients. Europa Medicophysica. 2003;39(4):181-9.

16 Tinetti ME, Richman D, Powell L. Falls efficacy as a measure of fear of falling. | Gerontol. 1990;45(6):P239-43.

17 Ferraresi G, Buganè F, Cosma M, Agarici M, Vio A, Manca M, et al. Timed up and go test (TUG) temporal phases assessment using a wireless device $\left(\right.$ free4act $\left.{ }^{\circledR}\right)$ : Method validation in healthy subjects. Gait Posture. 2013;37:30-1.

18 Paternostro-Sluga T, Grim-Stieger M, Posch M, Schuhfried O, Vacariu G, Mittermaier C, et al. Reliability and validity of the Medical Research Counci (MRC) scale and a modified scale for testing muscle strength in patients with radial palsy. J Rehabil Med. 2008;40(8):665-71.

19 Apolone G, Mosconi P. The Italian SF-36 Health Survey: translation, validation and norming. | Clin Epidemiol. 1998;51(11):1025-36.

20 Thompson PD, Arena R, Riebe D, Pescatello LS; American College of Sports Medicine. ACSM's new preparticipation health screening recommendations from ACSM's guidelines for exercise testing and prescription, ninth edition. Curr Sports Med Rep. 2013;12(4):215-7.

21 Carbonell-Baeza A, Aparicio VA, Ortega FB, Cuevas AM, Alvarez IC, Ruiz $I R$, et al. Does a 3-month multidisciplinary intervention improve pain, body composition and physical fitness in women with fibromyalgia? Br J Sports Med. 2011;45(15):1189-95

22 Häuser W, Klose P, Langhorst J, Moradi B, Steinbach M, Schiltenwolf M, et al. Efficacy of different types of aerobic exercise in fibromyalgia syndrome: a systematic review and meta-analysis of randomised controlled trials. Arthritis Res Ther. 2010;12(3):R79.

23 Latorre Román PÁ, Santos e Campos MA, García-Pinillos F. Effects of functional training on pain, leg strength, and balance in women with fibromyalgia. Mod Rheumatol. 2015;25(6):943-7.

24 Sañudo B, Galiano D, Carrasco L, Hoyo M, McVeigh JG. Effects of a prolonged exercise program on key health outcomes in women with fibromyalgia: a randomized controlled trial. J Rehabil Med. 2011;43(6):521-6.

25 Busch Al, Barber KA, Overend TI, Peloso PM, Schachter CL. Exercise for treating fibromyalgia syndrome. Cochrane Database Syst Rev. 2007;(4):CD003786.

26 Busch AJ, Webber SC, Richards RS, Bidonde J, Schachter CL, Schafer LA, et al. Resistance exercise training for fibromyalgia. Cochrane Database Syst Rev. 2013;(12):CD010884.

27 Kibar S, Yıldız HE, Ay S, Evcik D, Ergin ES. New approach in fibromyalgia exercise program: a preliminary study regarding the effectiveness of balance training. Arch Phys Med Rehabil. 2015;96(9):1576-82.

28 Duruturk N, Tuzun EH, Culhaoglu B. Is balance exercise training as effective as aerobic exercise training in fibromyalgia syndrome? Rheumatol Int. 2015;35(5):845-54.

29 Sañudo B, Carrasco L, Hoyo M, Oliva-Pascual-Vaca Á, Rodriguez-Blanco C. Changes in body balance and functional performance following whole-body vibration training in patients with fibromyalgia syndrome: a randomized controlled trial. J Rehabil Med. 2013;45(7):678-84.

30 Demir-Göçmen D, Altan L, Korkmaz N, Arabacı R. Effect of supervised exercise program including balance exercises on the balance status and clinical signs in patients with fibromyalgia. Rheumatol Int. 2013;33(3):743-50.

31 Panton LB, Figueroa A, Kingsley JD, Hornbuckle L, Wilson J, St John N, et al. Effects of resistance training and chiropractic treatment in women with fibromyalgia. J Altern Complement Med. 2009;15(3):321-8.

32 Valkeinen H, Alén M, Häkkinen A, Hannonen P, Kukkonen-Harjula K, Häkkinen $\mathrm{K}$. Effects of concurrent strength and endurance training on physical fitness and symptoms in postmenopausal women with fibromyalgia: a randomized controlled trial. Arch Phys Med Rehabil. 2008;89(9):1660-6.

33 Gusi N, Tomas-Carus P, Häkkinen A, Häkkinen K, Ortega-Alonso A. Exercise in waist-high warm water decreases pain and improves health-related quality of life and strength in the lower extremities in women with fibromyalgia. Arthritis Rheum. 2006;55(1):66-73.

34 Tomas-Carus P, Häkkinen A, Gusi N, Leal A, Häkkinen K, Ortega-Alonso A. Aquatic training and detraining on fitness and quality of life in fibromyalgia. Med Sci Sports Exerc. 2007;39(7):1044-50.

35 Gowans SE, deHueck A. Effectiveness of exercise in management of fibromyalgia. Curr Opin Rheumatol. 2004;16(2):138-42.

36 Akkaya N, Akkaya S, Atalay NS, Acar M, Catalbas N, Sahin F. Assessment of the relationship between postural stability and sleep quality in patients with fibromyalgia. Clin Rheumatol. 2013;32(3):325-31.

37 Tran ST, Thomas S, DiCesare C, Pfeiffer M, Sil S, Ting TV, et al. A pilot study of biomechanical assessment before and after an integrative training program for adolescents with juvenile fibromyalgia. Pediatr Rheumatol j. 2016;22;14(1):43.

38 Gusi N, Parraca |A, Olivares PR, Leal A, Adsuar |C. Tilt vibratory exercise and the dynamic balance in fibromyalgia: a randomized controlled trial. Arthritis Care Res (Hoboken). 2010;62(8):1072-8. 